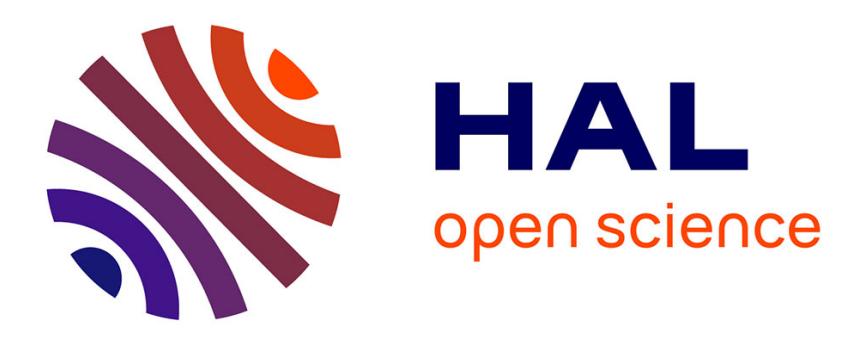

\title{
The temperature dependence of the electrical properties of thin tellurium films
}

A. de Vos, D. van Dhelsen

\section{To cite this version:}

A. de Vos, D. van Dhelsen. The temperature dependence of the electrical properties of thin tellurium films. Revue de Physique Appliquée, 1979, 14 (9), pp.815-820. 10.1051/rphysap:01979001409081500 . jpa-00244667

\section{HAL Id: jpa-00244667 https://hal.science/jpa-00244667}

Submitted on 1 Jan 1979

HAL is a multi-disciplinary open access archive for the deposit and dissemination of scientific research documents, whether they are published or not. The documents may come from teaching and research institutions in France or abroad, or from public or private research centers.
L'archive ouverte pluridisciplinaire HAL, est destinée au dépôt et à la diffusion de documents scientifiques de niveau recherche, publiés ou non, émanant des établissements d'enseignement et de recherche français ou étrangers, des laboratoires publics ou privés. 


\title{
The temperature dependence of the electrical properties of thin tellurium films
}

\author{
A. De Vos \\ Nationaal fonds voor wetenschappelijk onderzoek \\ and D. Van Dhelsen \\ Laboratorium voor elektronica en meettechniek, Rijksuniversiteit Gent, Sint Pietersnieuwstraat 41, \\ B-9000 Gent, Belgium
}

(Reçu le 7 février 1979, révisé le 7 juin 1979, accepté le 14 juin 1979)

\begin{abstract}
Résumé. - La mobilité de Hall $\mu$ et la concentration $p$ des trous dans les couches minces évaporées en Te de $130 \AA$ d'épaisseur sont étudiées en fonction de la température.

La façon dont la mobilité dépend de la température, montre que le plus important mécanisme de diffusion des trous sont des joints de grains et que le modèle de Petritz est valable.

La façon dont la concentration des porteurs de charge dépend de la température, montre que les couches sont dopées avec différents accepteurs, qui sont distribués uniformément dans la bande interdite.
\end{abstract}

\begin{abstract}
The Hall mobility $\mu$ and the concentration $p$ of the holes in thin evaporated Te films of $130 \AA$ thickness is investigated as a function of the temperature.

From the temperature dependence of the mobility, it is shown that the dominant scatterer of the holes are grain boundaries and that the Petritz-model is valid.

From the temperature dependence of the carrier concentration, it is shown that the films are doped with various acceptors, which are uniformly distributed in the forbidden energy gap.
\end{abstract}

1. Introduction. - Many authors have investigated the structure and the electrical properties of thin films of the elemental p-type semiconductor tellurium. Some of them have investigated the temperature dependence of the electrical properties.

Most of these studies were performed on films thicker than $1000 \AA$. For example, Capers and White [1] as well as Goswami and Ojha [2] give extensive results of Hall-measurements in the temperature range from $-200^{\circ} \mathrm{C}$ to $+100^{\circ} \mathrm{C}$, for films 1000 to $10000 \AA$ thick.

The purpose of the present paper is to investigate the temperature dependence of the electronic properties $\mu$, $p$ and $\sigma$ for Te thin films of $130 \AA$ thick. This thickness was chosen, because the use of Te films in thin film transistors requires a thickness ranging from 100 to $200 \AA[3,4,5,6]$.

Recently, some authors have published results in the thickness range 100 to $400 \AA$ : Okuyama and Kumagai [7] and Kubovy and Janda [8]. From the temperature dependence of the Hall-mobility, both teams conclude that the holes are scattered by grain boundaries. They give no model for the energy distribution of the acceptor doping that explains the temperature dependence of the hole concentration.

In the present paper we will fit the experimental temperature dependence of hole mobility and hole concentration with models of hole scattering and acceptor doping.

2. Experimental set-up. - In a vacuum plant, $99.999 \%$ pure Te-powder was evaporated from an $\mathrm{Al}_{2} \mathrm{O}_{3}$-crucible in a $\mathrm{Mo}$ boat source. The residual gas pressure varied in the range from $10^{-7}$ to $10^{-6}$ torr. The substrates were made of Corning glass 7059. During evaporation, they were kept at ambient temperature. The deposition rate was about $12 \AA / \mathrm{s}$.

The thickness of the Te films was $130 \AA$. A molibdenum mask provided the desired geometry of the film : eight cross-shaped samples on one substrate.

Gold contacts and a protecting layer of $1000 \AA$ 
silicon mono-oxide were evaporated in the same vacuum cycle. No post-deposition treatment was performed.

Resistivity and Hall-voltage measurements were undertaken by Van der Pauw's method [9], adapted for the cross shaped sample with electrical contacts of finite dimensions [10]. These measurements were performed in the temperature range from $-50^{\circ} \mathrm{C}$ to $+150^{\circ} \mathrm{C}$.

At room temperature the Hall mobility $\mu$ of the films was about $10 \mathrm{~cm}^{2} / \mathrm{Vs}$ and the hole concentration $p$ about $2 \times 10^{18} \mathrm{~cm}^{-3}$. The conductivity $\sigma=q \mu p$ was thus about $3 \Omega^{-1} \mathrm{~cm}^{-1}$. Wis will discuss now in detail the temperature dependence of these material constants, for one representative sample.

\section{Temperature dependence of the Hall mobility. -} We see from figure 1 that $\log \mu$ depends linearly on $1 / T$. So we can conclude that :

$$
\mu=\mu_{1} \exp \left(-\frac{\Phi_{1}}{k T}\right) .
$$

Linear regression gives

$$
\begin{aligned}
& \mu_{1}=120 \mathrm{~cm}^{2} / \mathrm{Vs} \\
& \Phi_{1}=66 \mathrm{meV} .
\end{aligned}
$$

Formula (1) is associated with the polycristalline nature of the Te films : scattering by grain boundaries. Indeed, if $\Phi$ denotes the height of the energy barriers at the grain boundaries, we have

$$
\mu=\mu_{0} \exp \left(-\frac{\Phi}{k T}\right)
$$

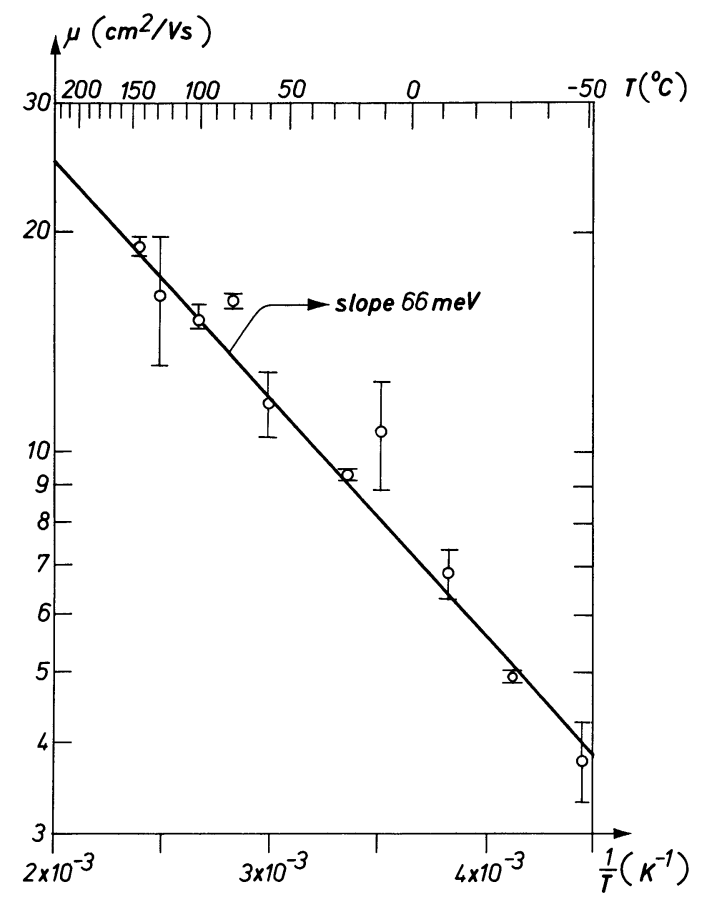

Fig. 1. - Hall mobility of a $130 \AA \mathrm{Te}$ film $: \log \mu$ versus $1 / T$.
As $\mu_{0}$ is temperature-dependent, $\mu_{0}$ and $\Phi$ of formula (4) cannot be associated immediately with $\mu_{1}$ and $\Phi_{1}$ of formula (1).

For the temperature dependence of the pre-exponential factor $\mu_{0}$, we will prove the validity of the Petritzmodel [11].

According to the Petritz-model, the factor $\mu_{0}$ is given by $[7,8,12,13]$ :

$$
\mu_{0}=\frac{q v_{\mathrm{th}}}{4 N k T},
$$

where $v_{\mathrm{th}}=$ the mean thermal velocity of the holes $N=$ the number of grain boundaries per unit length.

We will use

$$
v_{\mathrm{th}}=\left(3 k T / m_{\mathrm{h}}^{*}\right)^{1 / 2},
$$

and

$$
m_{\mathrm{h}}^{*} \approx 0.50 m_{0}
$$

where $m_{\mathrm{h}}^{*}=$ the effective mass of the holes

$m_{0}=$ the free electron mass.

Formula (7) is taken rather arbitrarily, because there seems to be no agreement on the value of $m_{\mathrm{h}}^{*}$ in tellurium. Indeed, table I shows the various values used by various authors.

Table I.

\begin{tabular}{llc}
\multicolumn{2}{c}{ Author } & \\
\multicolumn{1}{c}{$m_{\mathrm{h}}^{*} / m_{0}$} \\
Ghosh & & - \\
Smith & {$[14]$} & 1.00 \\
Dutton and Muller & {$[15]$} & 0.91 \\
Janda and Kubovy & {$[5]$} & 0.75 \\
Okuyama and Kumagai & {$[7]$} & 0.45 \\
& & 0.14
\end{tabular}

Whereas the value 0.91 is deduced from mobility and optical bandgap measurements, the value 0.45 is determined from thermo-emf data, the value 0.14 is calculated from the elastic stiffness constants and the numbers 1.00 and 0.75 are more or less tentative. The fact that $\mu_{0}$ is only proportional to $\left(m_{\mathrm{h}}^{*}\right)^{-1 / 2}$, guarantees that the arbitrary compromise $m_{\mathrm{h}}^{*}=0.50 m_{0}$ gives a result that is correct on a factor of 2 .

From (6) and (7) we get

$$
v_{\mathrm{th}} \approx 2 \times 10^{7} \frac{\mathrm{cm}}{\mathrm{s}} \times\left(\frac{T}{300 \mathrm{~K}}\right)^{1 / 2}
$$

We put $N \approx 1 / L$, where $L$ is the mean cristallite diameter. From electron micrographs we know that the films consist of a network of coalesced cristallites, about $200 \AA$ in diameter [17]. So we have

$$
N \approx 5 \times 10^{5} \mathrm{~cm}^{-1} \text {. }
$$


So formula (7) predicts

$$
\mu_{0} \approx 300 \frac{\mathrm{cm}^{2}}{\mathrm{Vs}} \times\left(\frac{T}{300 \mathrm{~K}}\right)^{-1 / 2} .
$$

In order to check the validity of the Petritz-model, a diagram of $\log \left[\mu\left(T / T_{0}\right)^{1 / 2}\right]$ versus $1 / T$ was plotted. This gives figure 2 (with $T_{0}=300 \mathrm{~K}$ ). We find indeed a linear dependence

$$
\mu\left(\frac{T}{T_{0}}\right)^{1 / 2}=205 \frac{\mathrm{cm}^{2}}{\mathrm{Vs}} \exp \left(-\frac{80 \mathrm{meV}}{k T}\right)
$$

from which we conclude that

$$
\mu_{0}=205 \frac{\mathrm{cm}^{2}}{\mathrm{Vs}} \times\left(\frac{T}{300 \mathrm{~K}}\right)^{-1 / 2}
$$

and

$$
\Phi=80 \mathrm{meV} .
$$

The good agreement between the experimental relation (12) and the predicted formula (10) makes us conclude that the Petritz-model is valid.

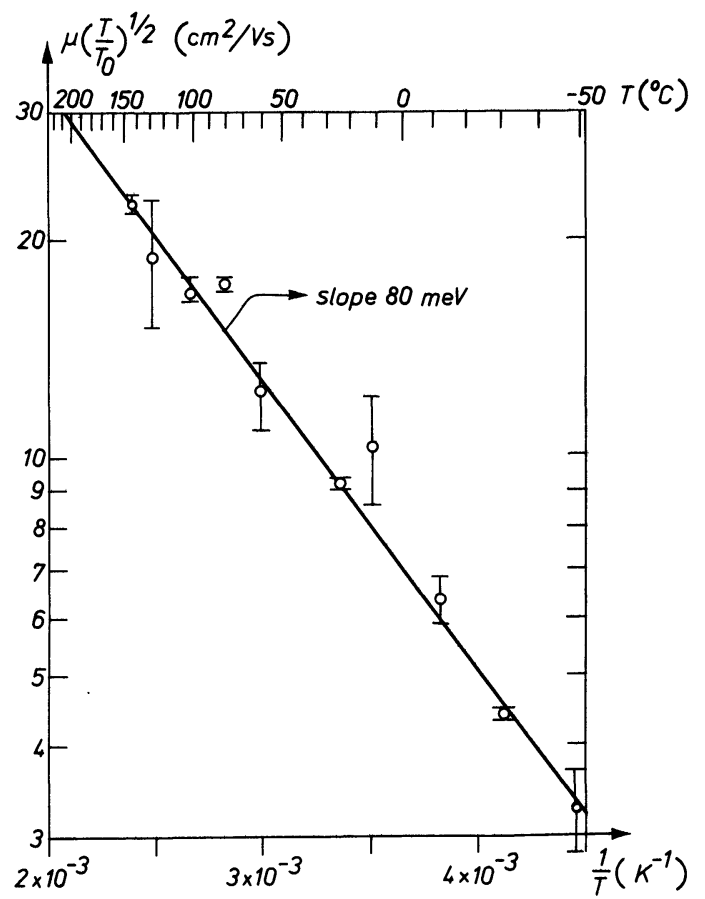

Fig. 2. - Hall mobility of a $130 \AA \mathrm{Te}$ film : $\log \left[\mu\left(T / T_{0}\right)^{1 / 2}\right]$ versus $1 / T$.

4. Temperature dependence of the hole concentration. - We see from figure 3 that $\log p$ shows a good linear dependence of $1 / T$. The activation energy $\Phi_{2}$ is small : $34 \mathrm{meV}$.

Different models of single acceptor levels and uniform acceptor bands have been tried. The numerical method used is similar to the one proposed by Van Calster and Reusens [18].

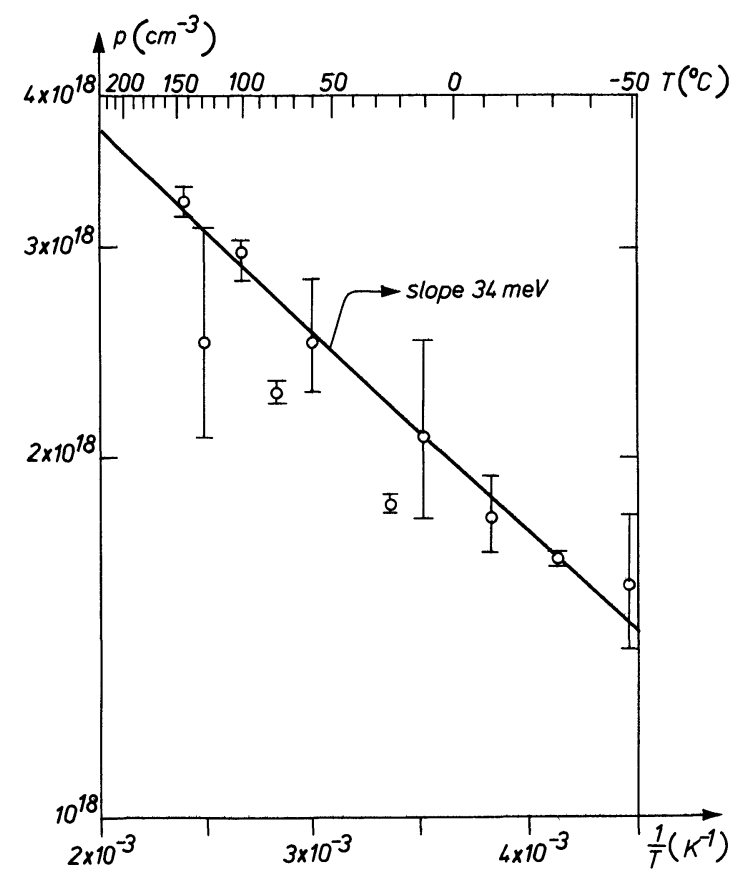

Fig. 3. - Hole concentration of a $130 \AA$ Te film $: \log p$ versus $1 / T$.

The electron and hole concentrations are computed by means of the Fermi-Dirac integral $F_{1 / 2}$ :

$$
\begin{aligned}
& n\left(E_{\mathrm{F}}\right)=N_{\mathrm{c}} F_{1 / 2}\left(\frac{E_{\mathrm{F}}-E_{\mathrm{c}}}{k T}\right) \\
& p\left(E_{\mathrm{F}}\right)=N_{\mathrm{v}} F_{1 / 2}\left(\frac{E_{\mathrm{v}}-E_{\mathrm{F}}}{k T}\right),
\end{aligned}
$$

where $E_{\mathrm{F}}=$ the Fermi-level

$N_{\mathrm{c}}=$ the effective density of states in the conduction band

$N_{\mathrm{v}}=$ the effective density of states in the valence band.

Using $m_{\mathrm{e}}^{*} \approx m_{\mathrm{h}}^{*} \approx 0.50 m_{0}$, we get

$N_{\mathrm{c}} \approx N_{\mathrm{v}} \approx 8.8 \times 10^{18} \mathrm{~cm}^{-3} \times\left(\frac{T}{300 \mathrm{~K}}\right)^{3 / 2}$.

The position of the Fermi-level is determined by solving the charge neutrality equation :

$$
N_{\mathrm{a}}^{-}\left(E_{\mathrm{F}}\right)+n\left(E_{\mathrm{F}}\right)-p\left(E_{\mathrm{F}}\right)=0,
$$

where $N_{\mathrm{a}}^{-}=$the concentration of ionized acceptors. For a single acceptor level with an energy $E_{\mathrm{a}}$ as well as for an acceptor band uniformly distributed between the energies $E_{1}$ and $E_{2}$, appropriate functions $N_{\mathrm{a}}^{-}\left(E_{\mathrm{F}}\right)$ are available [18].

Calculations showed that an acceptor band uniformly distributed within the bandgap $\left(E_{1}=E_{\mathrm{v}}\right.$, $E_{2}=E_{\mathrm{c}}$ ) gives the best correspondence between theory and experiment.

Such a uniform distribution of doping levels in the energy gap is often used as a model for amorphous 
or polycristalline semiconductors or insulators $[18$, 19].

The acceptor density $\mathrm{d} N_{\mathrm{a}} / \mathrm{d} E$ (in $\mathrm{cm}^{-3} \mathrm{eV}^{-1}$ ) is then equal to $N_{\mathrm{a}} / E_{\mathrm{g}}$.

After [18] the following approximation holds :

$$
p \approx\left(N_{\mathrm{v}} N_{\mathrm{a}} \frac{k T}{E_{\mathrm{g}}}\right)^{1 / 2}
$$

Taking the $T^{3 / 2}$ dependence of $N_{\mathrm{v}}$ into account, this means that the hole concentration $p$ is proportional to $T^{5 / 4}$. As a $T^{m}$ function behaves in a temperature range around a central temperature $T_{0}$ much as an $\exp (-\Phi / k T)$ dependence with activation energy $\Phi=m k T_{0}$, we can predict that $T^{5 / 4}$ will introduce a slope of about $33 \mathrm{meV}$ in the $\log p$ versus $1 / T$ diagram. As this is very close to the experimental $34 \mathrm{meV}$, the above model seems very well suited. And indeed a good curve fitting is possible for the whole temperature range under investigation : figure 4 . We see that (for $m_{\mathrm{h}}^{*}=0.50 m_{0}$ ) the acceptor concentration $N_{\mathrm{a}}$ is about $2.0 \times 10^{19} \mathrm{~cm}^{-3}$ (or $5.3 \times 10^{-19} \mathrm{~cm}^{-3} \mathrm{eV}^{-1}$ as $E_{\mathrm{g}}=0.37 \mathrm{eV}$ ). The uncertainty for $m_{\mathrm{h}}^{*}$ introduces a possible error in the determination of $N_{\mathrm{a}}$.

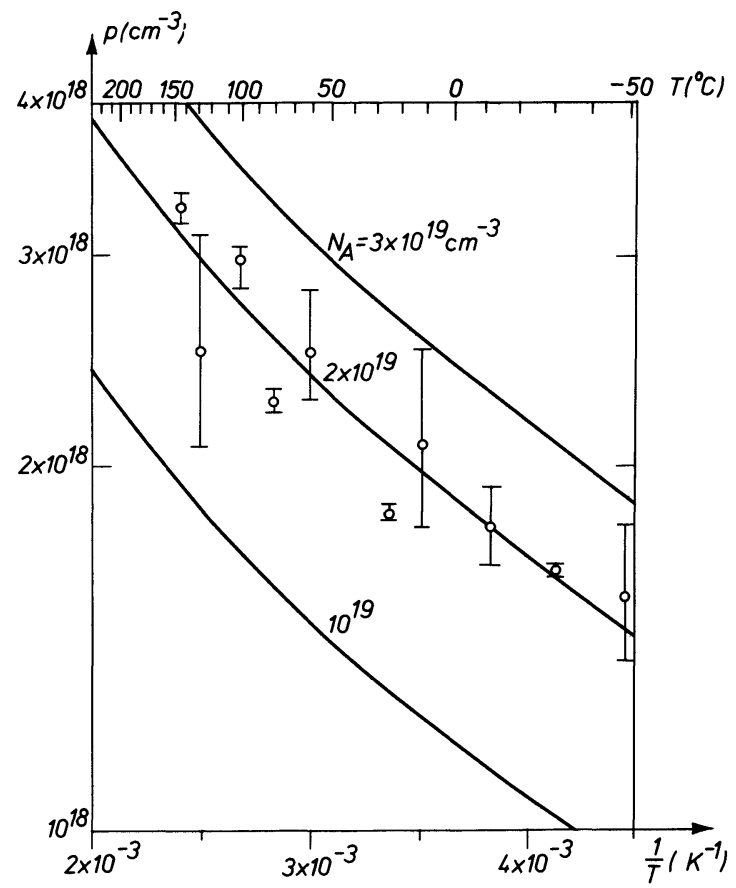

Fig. 4. - Hole concentration of a $130 \AA \mathrm{Te}$ film $: \log p$ versus $1 / T$, with curve-fitting for an acceptor doping uniformly distributed in the band gap.

We have to remark that the above mentioned calculations assume that we are dealing with bulk material (flat band conditions). As the investigated films are very thin, the effect of surface depletion layers might be important. Therefore we checked theoretically the influence of traps at the interfaces Te-SiO and Te-glass. We supposed these traps to be uniformly distributed in the energy gap of the semi- conductor, as is usually done by various authors [20, 21]. By solving the Poisson equation, it was possible to determine the hole concentration as a function of the depth, and thus also the average concentration. This is in fact the quantity that one measures with Hall experiments.

Figure 5 shows $p_{\text {bulk }}$ as well as $p_{\text {average }}$ for a particular example : a trap density of $3 \times 10^{12} \mathrm{~cm}^{-2}$ (or $7.8 \times 10^{12} \mathrm{~cm}^{-2} \mathrm{eV}^{-1}$ ).

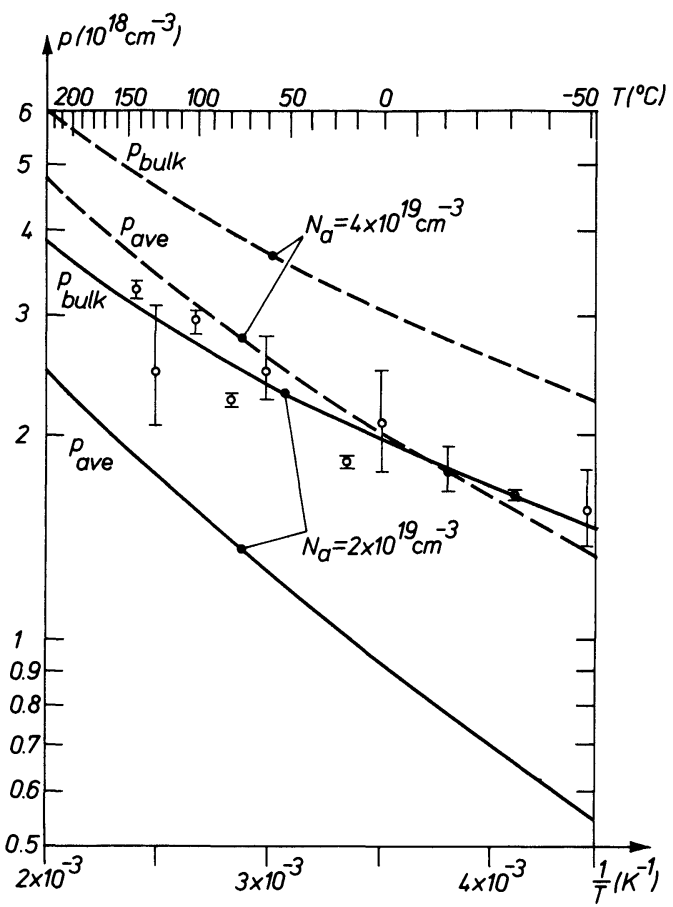

Fig. 5. - Hole concentration of a $130 \AA$ Te film : $\log p$ versus $1 / T$, influence of surface traps.

Similar and even smaller trap concentrations are observed at the interface of various thin film semiconductors and insulators $[5,20,22]$. We see again that for the acceptor concentration

$$
N_{\mathrm{a}}=2 \times 10^{19} \mathrm{~cm}^{-3}
$$

the bulk hole concentration fits well the experimental data. The average hole concentration is however much smaller, because of a considerable depletion layer. Choosing $N_{\mathrm{a}}=4 \times 10^{19} \mathrm{~cm}^{-3}$ gives an average carrier concentration curve close to the measured values. We can conclude that taking surface depletion into account does only affect appreciably the determination of the acceptor concentration $N_{\mathrm{a}}$. It has only little influence on the temperature dependence. Indeed the depletion depth is only weakly modulated by temperature, so that the temperature coefficient of the average $p$ is only little larger than that of the bulk $p$.

Apart from the surface depletion layer, we must also consider the depletion layers at the grain boundaries. For the barrier height measured $(80 \mathrm{meV})$ the depletion depth is not insignificant with respect 
to the grain diameter ( $200 \AA)$. However, it follows from the theory of Volger [23] that the Hall measurements determine a carrier concentration very close to the carrier concentration in the centre of the cristallite, so that the experimental results are only slightly affected by the aforementioned depletion layers.

\section{Temperature dependence of the conductivity $\sigma$.} Using our models for $\mu(T)$ and $p(T)$, we can now calculate the conductivity $\sigma$ as a function of the temperature. Figure 6 shows the results of this calculation.

Whereas the Hall mobility and the hole concentration measurements are corrupted with considerable uncertainties, the conductivity measurements are very accurate.

Therefore a comparison between experiment and theory for $\sigma(T)$ is an interesting supplementary check for our physical models. From figure 6 we see indeed a close agreement between experiment and theory.

6. Conclusions. - From the hole density data we have found that a uniform distribution of acceptors within the band gap is a good model for the Te films. It is a mathematical approximation for the structure (or lack of structure) of a thin film. The film has a spectrum of different lattice defects and impurities. These different kinds of acceptors, with their different concentrations and activation-energies, are well described by an acceptor-doping spread uniformly over the band gap. The total density of acceptors is about $2 \times 10^{19} \mathrm{~cm}^{-3}$.

The acceptors are partly ionized and fill the valence band with extrinsic holes, with a concentration of about $2 \times 10^{18} \mathrm{~cm}^{-3}$ at room temperature and with a weak temperature sensitivity, of the form $T^{5 / 4}$.

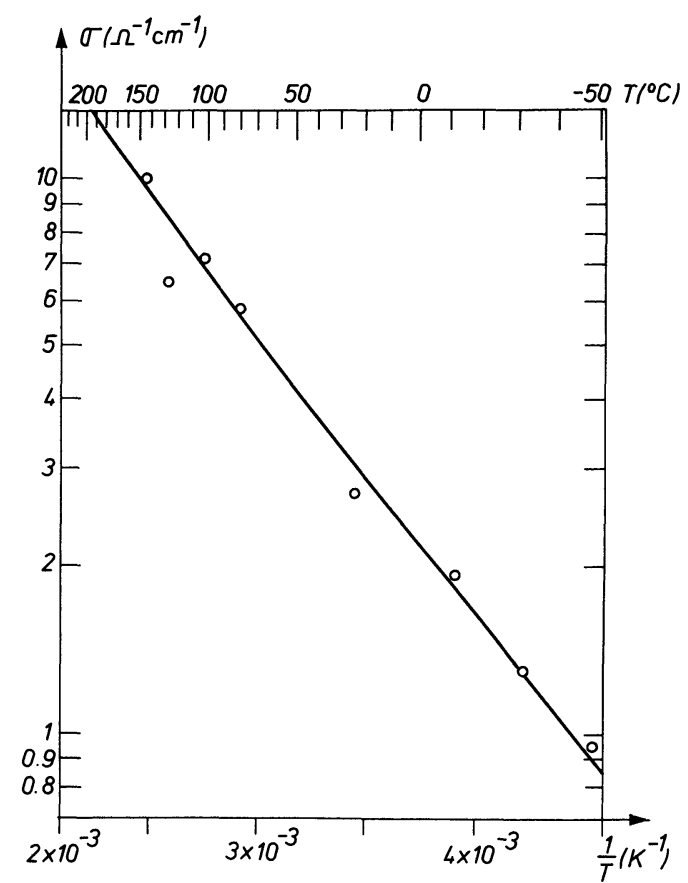

Fig. 6. - Conductivity of a $130 \AA$ Te film : $\log \sigma$ versus $1 / T$.

The mobility of the holes is low (about $10 \mathrm{~cm}^{2} / \mathrm{Vs}$ at room temperature) and strongly temperature dependent, due to grain boundary scattering. The Hall mobility data are very well explained by the Petritzmodel, who predicts a temperature law of the form $T^{-1 / 2} \exp (-\Phi / k T)$. The energy barrier $\Phi$ of the grain boundaries is $80 \mathrm{meV}$ high.

The conclusions on the doping model are new for Te thin films. The grain boundary scattering was already premised by Okuyama and Kumagai [7] and by Kubovy and Janda [8].

\section{References}

[1] CAPERS, M. and White, M., "The electrical properties of vacuum deposited tellurium films ", Thin Solid Films 15 (1973) $5-14$

[2] Goswami, A. and Ojнa, S., "Semiconducting properties of tellurium films ", Thin Solid Films 16 (1973) 187-197.

[3] Weimer, P., "A p-type Te thin-film transistor ", Proc. IEEE 52 (1964) 608-609.

[4] WiLSON, H. and GutTiERREZ, W., "Te TFT's exceed 100-MHz and one Watt capabilities", Proc. IEEE 55 (1967) 415416.

[5] Dutton, R. and Muller, R., " Electrical properties of Te thin films", Proc. IEEE 59 (1971) 1511-1517.

[6] Verma, B., Sharma, S., Parshad, R. and Malhotra, G., "Fabrication of Te thin film transistors", Indian J. Pure Appl. Phys. 5 (1967) 30-33.

[7] OkuYama, K. and KumagaI, Y., « Hall mobility of evaporated tellurium films ", Jpn. J. Appl. Phys. 12 (1973) 1884-1889.

[8] Kubovy, A. and JANDA, M., "Temperature dependence of hole mobilities in Te thin films ", Phys. Status Solidi (a) 36 (1976) 101-105.

[9] VAN DER PAUW, L., "A method of measuring specific resistivity and Hall effects of discs of arbitrary shape ", Philips Res. Rep. 13 (1958) 1-9.
[10] DE MEY, G., «Influence of sample geometry on Hall mobility measurements ", Archiv fur Elektronik und Uebertragungstechnik 27 (1973) 309-313.

[11] Petritz, R., «Theory of photoconductivity in semiconductor films ", Phys. Rev. 104 (1956) 1508-1516.

[12] Waxman, A., Henrich, V., Shallcross, F., Borkan, H. and WeIMER, P., "Electron mobility studies in surface space-charge layers in vapor-deposited CdS films ", $J$. Appl. Phys. 36 (1965) 168-175.

[13] ANDERson, J., "Barrier-limited conductivity in thin film transistors ", Thin Solid Films 37 (1976) 127-135.

[14] GHosH, S., «Variation of field effect mobility and Hall effect mobility with the thickness of the deposited films of tellurium ", J. Phys. and Chem. Solids 19 (1961) 61-65.

[15] Sмiтн, R., Semi-conductors (Cambridge University Press) 1968, p. 385.

[16] JANDA, M. and Kubovy, A., "Growth of vacuum-deposited tellurium films on glass substrates and some of their transport properties ", Phys. Status Solidi (a) 35 (1976) $391-402$

[17] De Vos, A. and AERTs, J., "The influence of deposition rate upon the electrical properties of thin tellurium films", Thin Solid Films 46 (1977) 223-228. 
[18] Van Calster, A. and Reusens, P., "The variation of resistivity with temperature for n-type degenerate indium antimonide films ", Thin Solid Films 44 (1977) 21-28.

[19] Lambert, M. and Mark, P., Current injection in solids (Academic Press, New York) 1970, pp. 25-27.

[20] Van Calster, A. and Pauwels, H., "Theoretical influence of surface states and bulk traps on thin film transistor characteristics ", Solid-State Electron. 18 (1975) 691-698.
[21] Refioglu, H. and De Massa, T., «TFT characteristics with uniformly distributed traps in the semiconductor ", SolidState Electron. 18 (1975) 720-721.

[22] Waxman, A. and MARK, G., "Improved stability in $\mathrm{Al}_{2} \mathrm{O}_{3}$ CdSe thin-film transistors ", Solid-State Electron. 12 (1969) 751-764.

[23] Volger, J., " Note on the Hall potential across an inhomogeneous conductor ", Phys. Rev. 79 (1950) 1023-1024. 